\title{
Hubungan Ketersediaan Jamban, Perilaku, dan Pengetahuan Masyarakat Dengan Buang Air Besar (BAB) di Kelurahan Legok Kecamatan Danau Sipin Kota Jambi Tahun 2018
}

\author{
Sondang Siahaan ${ }^{1}$, Rina Fauziah ${ }^{2}$ \\ 1,2Dosen Poltekkes Jambi \\ Correspondence email : fauziah.rina@yahoo.com
}

\begin{abstract}
Abstrak. Fasilitas jamban keluarga dimasyarakat terutama dalam pelaksanaannya tidaklah mudah, karena menyangkut peran serta masyarakat yang biasanya sangat erat kaitannya dengan perilaku, pengetahuan, dan kebudayaan. Ketersediaan jamban, perilaku, dan pengetahuan masyarakat dapat mempengaruhi BAB. Berdasarkan data dari puskesmas putri ayu, kelurahan legok memiliki jamban cemplung terbanyak yaitu 644 jamban. Tujuan penelitian ini adalah untuk mengetahui hubungan ketersediaan jamban, perilaku, dan pengetahuan masyarakat dengan BAB di Kelurahan Legok Kecamatan Danau Sipin Kota Jambi. Jenis penelitian ini adalah deskriptif analitik dengan pendekatan cross sectional. Penelitian ini dilakukan dengan kriteria inklusi. Sampel dalam penelitian ini adalah $87 \mathrm{KK}$. Hasil penelitian diperoleh bahwa ketersediaan jamban yang tersedia sebanyak $62 \mathrm{KK}$ sedangkan tidak tersedia sebanyak $25 \mathrm{KK}$, perilaku baik sebanyak $37 \mathrm{KK}$ sedangkan perilaku kurang baik sebanyak 50 kk, pengetahuan baik sebanyak 59 kk sedangkan pengetahuan kurang baik sebanyak 28 KK dan BAB di jamban sebanyak 62 KK sedangkan BAB di sungai sebanyak $25 \mathrm{KK}$. Kesimpulan ada hubungan yang bermakna antara ketersediaan jamban, perilaku, dan pengetahuan masyarakat dengan BAB. Saran dari penelitian ini adalah masyarakat membuat arisan jamban untuk pembuatan jamban dan septictank yang ditujukan kepada masyarakat yang belum memiliki jamban dan septictank.
\end{abstract}

Kata kunci: Jamban; Ketersediaan Jamban; Perilaku; Pengetahuan; BAB

\begin{abstract}
Family toilet facilities in the community, especially in their implementation, are not easy, because they involve community participation which is usually very closely related to behavior, knowledge, and culture. Availability of latrines, behavior, and community knowledge can influence bowel movements. Based on data from the ayu putri community health center, the Legok village has the most cemplung latrines, 644 latrines. The purpose of this study was to determine the relationship between the availability of latrines, behavior, and community knowledge with defecation in Legok Village, Danau Sipin District, Jambi City. This type of research is analytic descriptive with cross sectional approach. This research was conducted with inclusion criteria. The sample in this study was 87 households. The results showed that the availability of latrines was 62 households while there were not 25 households, $37 \mathrm{KKs}$ of good behavior while $50 \mathrm{kk}$ of bad behavior, $59 \mathrm{kk}$ of good knowledge while $28 \mathrm{KKs}$ of unfavorable knowledge and $62 \mathrm{KKs}$ in the latrine were $62 \mathrm{KK}$. while defecation in the river is 25 families. The conclusion is that there is a significant relationship between the availability of latrines, behavior, and community knowledge with BAB. Suggestions from this research are the community to make toilet arisan for making latrines and septic tanks aimed at people who do not have latrines and septic tanks.
\end{abstract}

Keywords: Latrine; Latrine Availability; Behavior; Knowledge; defecate

\section{PENDAHULUAN}

Pembangunan kesehatan sebagai salah satu upaya pembangunan nasional diarahkan guna terciptanya kesadaran, kemauan, dan kemampuan untuk hidup sehat bagi setiap penduduk agar dapat mewujudkan derajat kesehatan masyarakat yang optimal. Usaha-usaha untuk mencapai derajat kesehatan masyarakat yang optimal selalu diupayakan dan menyangkut semua segi baik fisik, mental, maupun sosial masyarakat. Salah satu permasalahan yang dihadapi Indonesia dalam pembangunan adalah masalah sanitasi. Sanitasi masih menjadi masalah pelik, terutama didaerah perdesaan, karena rendahnya tingkat pendidikan dan pengetahuan masyarakat. $\mathrm{Hal}$ ini menyebabkan banyaknya jamban yang tidak digunakan sebagaimana mestinya karena ketidakmengertian masyarakat. Tantangan pembangunan sanitasi indonesia adalah masalah sosial budaya dan perilaku penduduk yang terbiasa buang air besar (BAB) disembarang tempat, khususnya ke badan air yang juga digunakan untuk mencuci, mandi, dan kebutuhan higienis lainnya. (Priyoto, 2015). Penyediaan fasilitas sanitasi untuk aktivitas $B A B$ sangatlah penting, fasilitas sanitasi tersebut berupa jamban sehat. Menurut
WorldHealth Organization, yang dimaksud dengan meningkatkan fasilitassanitasi adalah fasilitas pembuangan ekskreta yang adekwat (per rumah atau kumpulan beberapa rumah,tetapi bukan kawasan pemukiman) yang dapat melindungi manusia maupun hewan dan tidak memungkinkan serangga terpapar dengan ekskreta. Toilet yang terhubung dengan sistem pembuangan limbah umum dengan sistem septik termasuk berkualitas, sedangkan latrin yang terbuka atau memerlukan pengurasan ekskreta secara manual termasuk tidak berkualitas. Dinegara berkembang, masih banyak terjadi pembuangan tinja secara sembarangan akibat tingkat sosial ekonomi yang rendah, pengetahuan dibidang kesehatan lingkungan yang kurang, dan kebiasaan buruk dalam pembuangan tinja yang diturunkan dari generasi ke generasi. (Budiman, 2012). Masalah tinja dan limbah cair juga berhubungan erat dengan masalah lingkungan hidup dan masalah kesehatan masyarakat. Masalah penyehatan lingkungan pemukiman khususnya pada jamban keluarga merupakan masalah kesehatan yang perlu mendapat prioritas. Fasilitas jamban keluarga dimasyarakat terutama dalam pelaksanaannya tidaklah mudah, karena menyangkut peran serta masyarakat 
yang biasanya sangat erat kaitannya perilaku, pengetahuan, dan kebudayaan. Pengetahuan, perilaku, dan ketersediaan jamban dapat mempengaruhi BAB. Perilaku adalah tindakan atau aktivitas dari manusia itu sendiri yang mempunyai bentangan yang sangat luas antara lain : berjalan, berbicara, menangis, tertawa, bekerja, menulis, membaca, dan sebagainya. Dari uraian diatas dapat disimpulkan bahwa yang dimaksud perilaku manusia adalah semua kegiatan atau aktivitas manusia, baik yang diamati langsung, maupun yang tidak dapat diamati oleh pihak luar. (Notoatmodjo,2014). Pengetahuan merupakan hasil dari tahu dan terjadi setelah seseorang melakukan penginderaan terhadap suatu objek tertentu. Penginderaan terjadi melalui panca indera manusia yakni indera penglihatan, pendengaran, penciuman, rasa, dan raba. Sebagian besar pengetahuan manusia diperoleh malalui mata dan telinga. (Fitriani, 2011). Pembuangan tinja yang dilakukan masyarakat tidak terlepas dari pengetahuan masyarakat dan perilaku masyarakat. Pengetahuan masyarakat yang baik belum tentu menentukan perilaku mereka dalam pembuangan tinja juga baik sebaliknya pengetahuan masyarakat yang kurang baik belum tentu perilaku mereka dalam pembuangan tinja tidak baik. $\mathrm{BAB}$ di sembarang tempat adalah kebiasaan masyarakat yang membuang tinja (sisa kotoran) nya disembarang tempat dan dapat berpotensi menyebarkan penyakit. Buang air besar sembarangan tidak hanya dilakukan masyarakat di kebun-kebun, sungai, ataupun tempat terbuka lainnya, melainkan melalui pipa pembuangan tinja yang dialirkan langsung ke sungai atau pun drainase juga termasuk $B A B$ yang tidak pada tempat semestinya karena pembuangan langsung melalui pipa ke sungai dapat mencemari sungai dan berpotensi menyebarkan penyakit. Tinja adalah bahan buangan yang dikeluarkan dari tubuh manusia. Pembuangan tinja secara tidak baik dan sembarangan dapat menyebabkan kontaminasi pada air, tanah, atau menjadi sumber infeksi, dan akan mendatangkan bahaya bagi kesehatan, karena penyakit yang tergolong water borne diseaseakan mudah berjangkit. Penyakit-penyakit yang dapat terjadi akibat keadaan diatas antara lain, disentri, diare, kolera, penyakit cacing, hepatitis viral dan beberapa penyakit infeksi lainnya. Kotoran dari manusia yang sakit dari suatu penyakit akan menjadi sumber infeksi, kotoran tersebut mengandung agen penyakit yang dapat ditularkan pada penjamu baru dengan perantara lalat. (Budiman, 2012)

Eksreta manusia (human exreta yang terdiri atas feses dan urine) merupakan hasil akhir dari proses yang berlangsung dalam tubuh manusia yang menyebabkan pemisahan dan pembuangan zat-zat yang tidak dibutuhkan oleh tubuh. Zat-zat yang tidak dibutuhkan oleh tubuh tersebut berupa tinja dan air seni (urine). (Budiman, 2012). Data Dinas Kesehatan Kota Jambi Tahun 2017 tentang ketersediaan jamban Di 20 Puskemas Kota Jambi sebagai berikut :

Tabel 1. Ketersediaan Jamban Per Puskesmas di Kota Jambi Tahun 2017

\begin{tabular}{|c|c|c|c|c|c|c|c|}
\hline \multirow[t]{2}{*}{ No } & \multirow[t]{2}{*}{ Puskesmas } & \multirow[t]{2}{*}{ Jumlah KK } & \multicolumn{5}{|c|}{ Jenis Jamban } \\
\hline & & & C & $\mathrm{CP}$ & $\mathrm{L}$ & LP & LST \\
\hline 1 & Putri Ayu & 9.131 & 1.903 & 0 & 1.835 & 0 & 1.631 \\
\hline 2 & Aur Duri & 4.687 & 252 & 294 & 0 & 97 & 3.502 \\
\hline 3 & Simp.IV Sipin & 8.539 & 143 & 95 & 0 & 72 & 8.022 \\
\hline 4 & Tanjung Pinang & 7.936 & 189 & 0 & 0 & 0 & 7.116 \\
\hline 5 & Payo Selincah & 5.690 & 0 & 54 & 0 & 391 & 5.236 \\
\hline 6 & Talang Banjar & 5.363 & 89 & 78 & 0 & 1.309 & 2.941 \\
\hline 7 & Pakuan Baru & 6.632 & 65 & 100 & 1.280 & 3.250 & 4.610 \\
\hline 8 & Talang Bakung & 12.769 & 107 & 237 & 337 & 529 & 9.209 \\
\hline 9 & Pal Merah I & 5.555 & 0 & 0 & 0 & 0 & 5.139 \\
\hline 10 & Pal Merah II & 4.660 & 0 & 4 & 0 & 0 & 3.441 \\
\hline 11 & Kebun Kopi & 4.375 & 96 & 298 & 0 & 336 & 3.558 \\
\hline 12 & Koni & 2.673 & 0 & 0 & 0 & 310 & 2.318 \\
\hline 13 & Olak Kemang & 3.444 & 0 & 6 & 0 & 169 & 2.051 \\
\hline 14 & Koni & 3.444 & 41 & 0 & 0 & 17 & 2.270 \\
\hline 15 & Simpang Kawat & 4.954 & 0 & 62 & 0 & 0 & 4.592 \\
\hline 16 & Tahtul Yaman & 5.320 & 106 & 277 & 350 & 180 & 470 \\
\hline 17 & Paal V & 13.868 & 167 & 0 & 688 & 54 & 11.825 \\
\hline 18 & Paal X & 10.952 & 0 & 0 & 0 & 0 & 0 \\
\hline 19 & Rawasari & 7.509 & 114 & 170 & 3.161 & 599 & 1.427 \\
\hline 20 & Kebun Handil & 9.029 & 319 & 350 & 856 & 402 & 5.797 \\
\hline & Jumlah & 136.430 & 3.663 & 2.025 & 8.507 & 7.715 & 83.155 \\
\hline
\end{tabular}

Sumber : Dinas Kesehatan Kota Jambi Tahun 2017

Data diatas menunjukkan bahwa puskesmas putri ayu memiliki jamban cemplung terbanyak yaitu 1.903 jamban. Puskesmas putri ayu terletak di Jalan Slamet Riyadi, Kelurahan Legok Kecamatan Danau Sipin Kota Jambi. Wilayah kerja puskesmas putri ayu ada 5 yaitu Kelurahan Legok, Kelurahan Murni, Kelurahan Solok Sipin, Kelurahan Sungai Putri Dan Kelurahan Selamat. $\mathrm{Di}$ Kelurahan Legok terdapat $40 \mathrm{RT}$ dengan jumlah 3.188 KK, Kelurahan Murni terdapat 21 RT dengan jumlah 1.255 KK, Kelurahan Solok Sipin terdapat 31 RT dengan jumlah $2.552 \mathrm{KK}$, Kelurahan Sungai Putri terdapat $23 \mathrm{RT}$ dengan Jumlah $2.136 \mathrm{KK}$ dan Kelurahan Selamat terdapat 32 RT dengan Jumlah 1.736 KK. Data tentang kepemilikan jamban di wilayah kerja Puskesmas Putri Ayu pada tahun 2017 yaitu di Kelurahan Legok memiliki jamban cemplung sebanyak 644 jamban, Kelurahan Murni 325 jamban, Kelurahan Solok Sipin 627 jamban, Kelurahan Sungai Putri Sebanyak 307 jamban, 
dan Kelurahan Selamat sebanyak 61 jamban. Ditahun 2017 kelurahan yang mempunyai jamban cemplung terbanyak yaitu Kelurahan Legok. Jamban cemplung termasuk jamban yang tidak saniter. Ketersediaan jamban yang tidak saniter seperti membuang kotorannya langsung ke sungai termasuk $B A B$ yang tidak pada tempat yang semestinya. Berdasarkan hasil survei pendahuluan yang dilakukan peneliti dengan memberikan kuesioner dan checklist kepada 10 responden. Dari 10 (sepuluh) responden di Kelurahan Legok didapatkan hasil responden yang kurang pengetahuannya tentang Jamban yaitu sebanyak 7 orang dan responden yang baik pengetahuannya tentang Jamban yaitu sebanyak 3 orang, responden yang memliki perilaku BAB kurang baik yaitu sebanyak 6 orang dan responden yang memiliki perilaku yang baik saat $B A B$ sebanyak 4 orang responden, responden yang memiliki jamban dirumah sebanyak 6 orang dan responden yang tidak memiliki jamban di rumah sebanyak 4 orang dan 4 orang responden tersebut yang membuang tinja (kotorannya) ke sungai. Dari 4 orang inilah yang dapat menyebabkan pencemaran air yang berasal dari tinja yang mereka keluarkan setiap hari. Sedangkan berdasarkan hasil observasi dari 10 orang responden, apabila dilihat dari segi lingkungan, 4 orang responden tersebut masih $\mathrm{BAB}$ di sungai. Berdasarkan latar belakang diatas maka peneliti tertarik untuk melakukan penelitian tentang "Hubungan Ketersediaan Jamban, Perilaku, Dan Pengetahuan Masyarakat Dengan Buang Air Besar (BAB) Di Kelurahan Legok Kecamatan Danau Sipin Kota Jambi Tahun 2018".

Bagaimana hubungan ketersediaan jamban, perilaku, dan pengetahuan masyarakat dengan Buang Air Besar (BAB) di Kelurahan Legok Kecamatan Danau Sipin Kota Jambi? Untuk mengetahui hubungan Ketersedian Jamban, Perilaku, dan Pengetahuan masyarakat dengan Buang Air Besar (BAB) Kelurahan Legok Kecamatan Danau Sipin Kota Jambi.

1. Untuk mengetahui hubungan Ketersediaan Jamban dengan BAB di Kelurahan Legok Kecamatan Danau Sipin Kota Jambi.

2. Untuk mengetahui hubungan Perilaku masyarakat dengan BAB di Kelurahan Legok Kecamatan Danau Sipin Kota Jambi.

3. Untuk mengetahui hubungan Pengetahuan masyarakat dengan BAB di Kelurahan Legok Kecamatan Danau Sipin Kota Jambi.

\section{METODE PENELITIAN}

Jenis penelitian ini adalah Deskriptif analitik dengan Pendekatan Cross sectional, merupakan suatu penelitian yang mempelajari hubungan antara faktor risiko (independen) dengan faktor efek (dependen), atau pengukuran variabel dilakukan pada waktu yang bersamaan. Lokasi penelitian dilakukan di Kelurahan Legok KecamatanDanau Sipin Kota Jambi. Penelitian dilakukan pada bulan Maret sampai dengan Mei Tahun 2018.

\section{Variabel Bebas}

Penelitian ini memiliki beberapa variabel, yaitu:

Variabel Bebas adalah variabel yang mempengaruhi variabel terikat. Adapun sebagai variabel bebas yakni ketersediaan jamban, perilaku masyarakat, dan pengetahuan masyarakat.

\section{Variabel Terikat}

Variabel terikat adalah variabel yang dipengaruhi oleh variabel bebas. Adapun sebagai variabel terikat yakni BAB di Kelurahan Legok Kecamatan Danau Sipin Kota Jambi.

Hipotesis yang diajukan dalam penelitian ini adalah hipotesis alternatif $(\mathrm{Ha})$ yaitu :

a. Ada hubungan Ketersediaan Jamban dengan BAB di Kelurahan Legok Kecamatan Danau Sipin Kota Jambi.

b. Ada hubungan Perilaku masyarakat dengan BAB di kelurahan Legok Kecamatan Danau Sipin Kota Jambi.

c. Ada hubungan Pengetahuan masyarakatdengan BAB di kelurahan Legok Kecamatan Danau Sipin Kota Jambi.

Populasi merupakan seluruh objek (manusia, binatang percobaan, dan data laboratorium) yang akan diteliti dan memenuhi karakteristik yang ditentukan. (Riyanto,2011)

Populasi dalam penelitian ini adalah seluruh KK yang ada di Kelurahan Legok Kecamatan Danau Sipin Kota Jambi. Adapun jumlah KK Di RT yang ada di sepanjang sungai di Kelurahan Legok Kecamatan Danau Sipin Kota Jambi yaitu 967 KK. Sampel merupakan sebagian dari populasi yang diharapkan dapat mewakili populasi. Menurut Lameshow dalam Agus Riyanto (2011) pengambilan sampel dalam penelitian ini berdasarkan sampel penelitian dengan menggunakan rumus sebagai berikut :

$$
\begin{aligned}
& N Z(1-\alpha / 2)^{2} \mathrm{P}(1-\mathrm{P}) \\
& \mathrm{n}=\overline{N d^{2}+Z(1-\alpha / 2)^{2} \mathrm{P}(1-\mathrm{P})} \\
& (967)(1,96)^{2} 0,5(1-0,5) \\
& =\overline{967(0,1)^{2}+(1,96)^{2} 0,5(1-0,5)} \\
& 967(3,8416) 0,5(0,5) \\
& =\overline{967(0,01)+(3,8416) 0,5(0,5)} \\
& 928,7068 \\
& =\overline{10,6304} \\
& =87,36 \\
& =87 \\
& \text { Keterangan } \\
& \mathrm{n}=\text { Besar Sampel } \\
& \mathrm{N}=\text { Besar Populasi } \\
& =\text { Besar penyimpangan }=0,1
\end{aligned}
$$
bahwa total sampel yang akan di teliti dari penelitian ini sebesar 87 KK (Responden). Cara pengambilan sampel dilakukan dengan kriteria inklusi yaitu hanya mengambil sampel didaerah (RT) di pinggiran sungai saja. Instrumen yang digunakan dalam penelitian ini adalah kuesioner dan checklist untuk mengetahui ketersediaan 
jamban, perilaku, pengetahuan masyarakat dan BAB di

Kelurahan Legok Kecamatan Danau Sipin Kota Jambi.

Kuesioner adalah pertanyaan yang diberikan kepada responden diantaranya :

a. Pengetahuan masyarakat tentang Jamban yang terdiri dari 13 pertanyaan dengan pilihan jawaban a dan b. Dengan uraian a : Tahu b : Tidak Tahu. Cara menjawab pertanyaan tentang pengetahuan dengan cara memberikan tanda silang $(X)$ pada pilihan jawaban yang dianggap benar oleh responden.

b. $B A B$, Responden memilih jawaban yang sesuai dengan tempat dimana responden BAB.

\section{Checklist}

a. Ketersediaan jamban di rumah responden terdiri dari 5 pernyataan dengan pilihan jawaban Tersedia dan Tidak Tersedia. Cara menjawab pernyataan tentang ketersedian jamban di rumah responden dengan cara memberikan tanda centang $(\sqrt{ })$ pada pilihan jawaban yang sesuai dengan ketersediaan jamban di rumah responden.

b. Perilaku masyarakat setelah BAB yang terdiri dari 4 pernyataan dengan pilihan jawaban ya dan tidak. Cara menjawab pernyataan tentang perilaku responden dengan cara memberikan tanda centang $(\sqrt{ })$ pada pilihan jawaban yang sesuai dengan perilaku responden.

Pengumpulan data dalam penelitian ini yaitu:

Data primer diperoleh secara langsung dilapangan melalui pemberian kuesioner kepada responden dan pengamatan tentang Ketersediaan Jamban, Perilaku, Pengetahuan, dan BAB di Kelurahan Legok Kecamatan Danau Sipin Kota Jambi.

Data sekunder diperoleh dari Dinas Kesehatan Kota Jambi dan Puskesmas Putri Ayu Kota Jambi berupa laporan tahunan.

Teknik pengolahan data didalam penelitian ini dengan tahapan sebagai berikut :

a. Editing

Tahap ini dilakukan dengan memeriksa kembali kuesioner yang telah dikumpulkan dengan meneliti kelengkapan, kejelasan, dan konsistensi dari setiap jawaban responden pada kuesioner dan checklist tentang Ketersediaan jamban, Perilaku, Pengetahuan dan BAB di Kelurahan Legok Kecamatan Danau Sipin Kota Jambi.

b. Coding

Coding merupakan kegiatan mengklasifikasikan data dengan memberi kode pada masing-masing pertanyaan. Pemberian dilakukan untuk menyederhanakan data yang diperoleh melalui kuesioner dan checklist tentang Ketersediaan Jamban, Perilaku, Pengetahuan dan BAB di Kelurahan Legok Kecamatan Danau Sipin Kota Jambi. Untuk variabel ketersediaan jamban jika jawaban Tersedia $=1$, jika jawaban Tidak Tersedia $=$ 0 . Variabel perilaku masyarakat,jika jawaban $Y a=1$, jika jawaban Tidak $=0$. Untuk variabel pengetahuan jika jawaban Tahu $=1$, jika jawaban Tidak tahu $=0$.

c. Entry Data

Pada tahap ini, setelah dilakukan pengkodean terhadap kuesioner dan checklist Ketersediaan jamban, Perilaku, Pengetahuan, dan BAB di Kelurahan Legok Kecamatan Danau Sipin Kota Jambi. Memasukkan data dari kuesioner dan checklist yang telah didapatkan ke program SPSS.

d. Tabulating

Memasukkan data Ketersediaan Jamban, Perilaku, Pengetahuan dan BAB masyarakat yang sebelumnya telah dilakukan proses editing dan coding ke dalam bentuk tabel.

e. Scoring

Scoring dilakukan dengan menggunakan skor (nilai) pada setiap pertanyaan dan pernyataan pada kuesioner dan checklist tentang Ketersediaan jamban, Perilaku, Pengetahuan, dan BAB. Kelurahan Legok Kecamatan Danau Sipin Kota Jambi. Untuk ketersediaan jamban yang tersedia diberi nilai 1, jika ketersediaan jamban tidak tersedia diberi nilai 0 . Untuk perilaku masyarakat yang baik diberi nilai 1 dan untuk perilaku masyarakat yang kurang baik diberi nilai 0 . Untuk pengetahuan masyarakat yang baik diberi nilai 1 dan untuk pengetahuan masyarakat yang kurang baik diberi nilai 0 .

f. Processing

Setelah semua isian kuesioner dan checklist terisi maka langkah selanjutnya adalah memproses (Processing) data agar dapat dianalisis tentang Ketersediaan jamban, Perilaku, Pengetahuan, dan BAB di Kelurahan Legok Kecamatan Danau Sipin Kota Jambi.

g. Cleaning

Pembersihan data (cleaning) merupakan kegiatan yang dilakukan untuk melihat kembali data yang telah dimasukkan atau sudah di entry dan tidak ada kesalahan dalam memasukkan data.

\section{Analisis Data \\ Analisis Univariat}

Analisis univariat dilakukan secara deskriptif dengan menggunakan tabel distribusi frekuensi, untuk mendeskripsikan variabel Ketersediaan jamban, Perilaku, dan Pengetahuan Masyarakat dengan BAB di Kelurahan Legok Kecamatan Danau Sipin Kota Jambi.

\section{Analisis Bivariat}

Analisis data yang digunakan dalam penelitian ini adalah analisis bivariat.Uji statistik yang digunakan adalah uji Chi-square dengan kemaknaan hasil perhitungan statistik digunakan Confident Interval 95\%. Hasil uji menyatakan ada hubungan jika $p$-Value $<0.05$ sedangkan jika $p$-Value> 0.05 yang berarti tidak ada hubungan.

\section{HASIL DAN PEMBAHASAN}

Kelurahan Legok Merupakan Salah Satu Wilayah Kerja Puskesmas Putri Ayu. Kelurahan Legok secara administrasi terletak di wilayah Kecamatan Danau Sipin Kota Jambi. Luas wilayah kelurahan legok yaitu 340 $\mathrm{km}^{2}$. Secara Geografis Kelurahan Legok berbatasan dengan :
a. Sebelah Utara
b. Sebelah Selatan
Sungai Batanghari
c. Sebelah Barat
d. Sebelah Timur
: Murni
: Kelurahan Beringin
: Sungai Putri 


\section{Hasil Analisis Univariat}

Ketersediaan Jamban

Ketersediaan jamban masyarakat di Kelurahan Legok Kecamatan Danau Sipin Kota Jambi dapat dilihat pada tabel berikut :

Tabel 2. Distribusi Frekuensi Ketersediaan Jamban Masyarakat Di Kelurahan Legok Kecamatan Danau Sipin Kota Jambi Tahun 2018

\begin{tabular}{cccc}
\hline No & $\begin{array}{c}\text { Ketersediaan } \\
\text { Jamban }\end{array}$ & Frekuensi & $\begin{array}{c}\text { Persentase } \\
(\%)\end{array}$ \\
\hline 1 & Tersedia & 62 & 71,3 \\
2 & Tidak Tersedia & 25 & 28,7 \\
& Total & 87 & 100,0 \\
\hline
\end{tabular}

Berdasarkan tabel 2 dapat dilihat bahwa ketersediaan jamban yang tersedia adalah sebanyak 62 KK $(71,3 \%)$ dan Ketersediaan jamban yang tidak tersedia adalah sebanyak $25 \mathrm{KK}(28,7 \%)$.

\section{Perilaku Masyarakat}

Perilaku Masyarakat di Kelurahan Legok Kecamatan Danau Sipin Kota Jambi dapat dilihat pada tabel berikut :

Tabel 3. Distribusi Frekuensi Perilaku Masyarakat Di Kelurahan Legok Kecamatan Danau Sipin Kota Jambi Tahun 2018

\begin{tabular}{cccc}
\hline No & Perilaku & Frekuensi & Persentase (\%) \\
\hline 1 & Baik & 37 & 42,5 \\
2 & Kurang Baik & 50 & 57,5 \\
& Total & 87 & 100,0 \\
\hline
\end{tabular}

Berdasarkan tabel 3 dapat dilihat bahwa Responden yang memiliki perilaku baik adalah sebanyak 37 KK $(42,5 \%)$ dan Responden yang memiliki perilaku kurang baik adalah sebanyak $50 \mathrm{KK}(57,5 \%)$.

\section{Pengetahuan Masyarakat}

Tabel 6. Hubungan Ketersediaan Jamban Dengan BAB Di Kelurahan Legok Kecamatan Danau Sipin Kota Jambi Tahun 2018

\begin{tabular}{|c|c|c|c|c|c|c|c|c|}
\hline \multirow{3}{*}{ Ketersediaan Jamban } & \multicolumn{4}{|c|}{ BAB } & \multirow{2}{*}{\multicolumn{2}{|c|}{ Total }} & \multirow{3}{*}{$\begin{array}{c}\mathrm{OR} \\
(95 \% \mathrm{Cl})\end{array}$} & \multirow{3}{*}{$p$-Value } \\
\hline & \multicolumn{2}{|c|}{ Sungai } & \multicolumn{2}{|c|}{ Jamban } & & & & \\
\hline & $\mathrm{n}$ & $\%$ & $\mathrm{~N}$ & $\%$ & $\mathrm{n}$ & $\%$ & & \\
\hline Tersedia & 0 & 0,0 & 62 & 100,0 & 62 & 100,0 & & \\
\hline Tidak Tersedia & 25 & 100,0 & 0 & 0,0 & 25 & 100,0 & 0 & 0,000 \\
\hline Total & 25 & 28,7 & 62 & 71,3 & 87 & 100,0 & & \\
\hline
\end{tabular}

Berdasarkan tabel 6 dapat dilihat bahwa ketersediaan jamban masyarakat di pinggiran sungai yang tersedia jamban yaitu sebanyak $62 \mathrm{KK}$, ketersediaan jamban yang tersedia dengan $B A B$ di sungai adalah sebanyak $0 \mathrm{KK}(0,0 \%)$ dan ketersediaan jamban yang tersedia dengan $\mathrm{BAB}$ di jamban adalah sebanyak 62 KK (100,0\%), Sedangkan untuk ketersediaan jamban yang tidak tersedia sebanyak 25 $\mathrm{KK}$, ketersediaan jamban yang tidak tersedia dengan BAB di sungai adalah sebanyak 25 KK (100,0\%) dan ketersediaan jamban tidak tersedia dengan $\mathrm{BAB}$ di jamban sebanyak $0 \mathrm{KK}(0,0 \%)$. Berdasarkan hasil uji
Pengetahuan masyarakat di Kelurahan Legok Kecamatan Danau Sipin Kota Jambi dapat dilihat pada tabel berikut :

Tabel 4. Distribusi Frekuensi Pengetahuan Masyarakat Di Kelurahan Legok Kecamatan Danau Sipin Kota Jambi Tahun 2018

\begin{tabular}{cccc}
\hline No & Pengetahuan & Frekuensi & Persentase (\%) \\
\hline 1 & Baik & 59 & 67,8 \\
2 & Kurang Baik & 28 & 32,2 \\
& Total & 87 & 100,0 \\
\hline
\end{tabular}

Berdasarkan tabel 4 dapat dilihat bahwa Responden yang memiliki pengetahuan baik adalah sebanyak 59 KK $(67,8 \%)$ dan Responden yang memiliki pengetahuan kurang baik adalah sebanyak $28 \mathrm{KK}$ $(32,2 \%)$.

\section{Buang Air Besar}

BAB yang dilakukan oleh masyarakat di Kelurahan Legok Kecamatan Danau Sipin dapat dilihat pada tabel berikut :

Tabel 5. Distribusi Frekuensi BAB Masyarakat Di Kelurahan Legok Kecamatan Danau Sipin Kota Jambi Tahun 2018

\begin{tabular}{cccc}
\hline No & Buang Air Besar & Frekuensi & Persentase (\%) \\
\hline 1 & Jamban & 62 & 71,3 \\
2 & Sungai & 25 & 28,7 \\
& Total & 87 & 100,0 \\
\hline
\end{tabular}

Berdasarkan tabel 5 dapat dilihat bahwa BAB Responden yang di jamban adalah sebanyak $62 \mathrm{KK}$ $(71,3 \%)$ dan Responden yang BAB di Sungai adalah sebanyak $25 \mathrm{KK}(28,7 \%)$.

\section{Hasil Analisis Bivariat}

Hubungan ketersediaan jamban dengan BAB dapat dilihat pada tabel berikut : statistik diperoleh $p$-Value $0,000<0,05$ Ho ditolak, berarti ada hubungan yang bermakna antara ketersediaan jamban dengan BAB di Kelurahan Legok Kecamatan Danau Sipin Kota Jambi Tahun 2018.

Hasil analisis tidak ditemukan nilai OR untuk ketersediaan jamban dengan $\mathrm{BAB}$ dikarenakan $p$-Value yang didapat yaitu sebesar 0,000 .

\section{Hubungan Perilaku Masyarakat Dengan BAB}

Hubungan perilaku dengan $B A B$ masyarakat dapat dilihat pada tabel berikut : 
Sondang Siahaan dan Rina Fauziah, Hubungan Ketersediaan Jamban, Perilaku, dan Pengetahuan Masyarakat Dengan Buang Air Besar (BAB) di Kelurahan Legok Kecamatan Danau Sipin Kota Jambi Tahun 2018

Tabel 7. Hubungan Perilaku Masyarakat Dengan BAB Di Kelurahan Legok Kecamatan Danau Sipin Kota Jambi Tahun 2018

\begin{tabular}{ccccccccc}
\hline \multirow{2}{*}{ Perilaku } & \multicolumn{2}{c}{ Sungai } & \multicolumn{2}{c}{ Jamban } & \multicolumn{2}{c}{ Total } & OR (95\% Cl) & $p$-Value \\
& $\mathrm{n}$ & $\%$ & $\mathrm{n}$ & $\%$ & $\mathrm{n}$ & $\%$ & \\
\hline Baik & 0 & 0 & 37 & 100,0 & 37 & 100,0 & \multirow{2}{*}{0,002} \\
Kurang Baik & 25 & 50,0 & 25 & 50,0 & 50 & 100,0 & 5,920 \\
Total & 25 & 28,7 & 62 & 71,3 & 87 & 100,0 & & \\
\hline
\end{tabular}

Berdasarkan tabel 7 dapat dilihat bahwa perilaku masyarakat dipinggiran sungai yang baik yaitu sebanyak $37 \mathrm{KK}$, Responden yang memiliki perilaku baik dengan BAB di Sungai adalah sebanyak $0 \mathrm{KK}(0,0 \%)$ dan responden yang memiliki perilaku baik dengan $\mathrm{BAB}$ di Jamban sebanyak $37 \mathrm{KK}(100,0 \%)$ sedangkan untuk perilaku masyarakat yang kurang baik sebanyak $50 \mathrm{KK}$, Responden yang perilakunya kurang baik dengan BAB di sungai yaitu sebanyak $25 \mathrm{KK}(50,0 \%)$ dan responden yang perilakunya kurang baik dengan BAB di Jamban sebanyak $25 \mathrm{KK}$ (50,0\%). Berdasarkan hasil uji statistik diperoleh $p$-Value $0,002<0,05$ Ho ditolak, berarti ada hubungan yang bermakna perilaku masyarakat dengan BAB di Kelurahan Legok Kecamatan Danau Sipin Kota Jambi Tahun 2018.

Hasil analisis juga diperoleh nilai OR $=5,920$ artinya responden yang memiliki perilaku kurang baik mempunyai peluang 5,92 kali untuk BAB di jamban di bandingkan dengan responden yang perilakunya baik untuk BAB di jamban.

\section{Hubungan Pengetahuan Masyarakat Dengan BAB}

Hubungan pengetahuan masyarakat dengan BAB dapat dilihat pada tabel berikut :

Tabel 8. Hubungan Pengetahuan Masyarakat Dengan BAB Di Kelurahan Legok Kecamatan Danau Sipin Kota Jambi Tahun 2018

\begin{tabular}{|c|c|c|c|c|c|c|c|c|}
\hline \multirow{3}{*}{ Pengetahuan } & \multicolumn{4}{|c|}{ BAB } & \multirow{2}{*}{\multicolumn{2}{|c|}{ Total }} & \multirow{3}{*}{$\begin{array}{c}\text { OR } \\
(95 \% \mathrm{Cl})\end{array}$} & \multirow{3}{*}{$p$-Value } \\
\hline & \multicolumn{2}{|c|}{ Sungai } & \multicolumn{2}{|c|}{ Jamban } & & & & \\
\hline & $\mathrm{n}$ & $\%$ & $\mathrm{~N}$ & $\%$ & $\mathrm{n}$ & $\%$ & & \\
\hline Baik & 10 & 16,9 & 49 & 83,1 & 59 & 100,0 & & \\
\hline kurang Baik & 15 & 53,6 & 13 & 46,4 & 28 & 100,0 & 5,654 & 0,001 \\
\hline Total & 25 & 28,7 & 62 & 71,3 & 87 & 100,0 & & \\
\hline
\end{tabular}

Berdasarkan tabel 8 dapat dilihat bahwa pengetahuan masyarakat di pinggiran sungai yang baik yaitu $59 \mathrm{KK}$, Responden yang pengetahuannya baik dengan BAB di sungai adalah sebanyak $10 \mathrm{KK}(16,9 \%)$ dan Responden yang pengetahuannya baik dengan BAB di Jamban sebanyak 49 KK (83,1\%) Sedangkan untuk pengetahuan responden yang kurang baik dengan BAB di sungai adalah sebanyak $15 \mathrm{KK}$ (53,6\%) dan Responden yang pengetahuannya kurang baik dengan $\mathrm{BAB}$ di jamban adalah sebanyak $13 \mathrm{KK}(46,4 \%)$. Berdasarkan hasil uji statistik diperoleh p-Value 0,001< 0,05 Ho ditolak, berarti ada hubungan yang bermakna antara pengetahuan masyarakat dengan BAB di Kelurahan Legok Kecamatan Danau Sipin Kota Jambi Tahun 2018. Hasil analisis juga diperoleh nilai OR = 5,654 artinya responden yang memiliki pengetahuan kurang baik mempunyai peluang 5,65 kali untuk BAB di jamban dibandingkan dengan pengetahuan yang baik untuk BAB di jamban.

\section{Pembahasan \\ Hubungan Ketersediaan Jamban Dengan BAB}

Hasil diketahui bahwa ketersediaan jamban masyarakat di pinggiran sungai yang tersedia dengan $\mathrm{BAB}$ di sungai sebanyak $0 \mathrm{KK}(0 \%)$ dan $\mathrm{BAB}$ di jamban sebanyak 62 KK $(71,3 \%)$, sedangkan untuk ketersediaan jamban masyarakat di pinggiran sungai yang tidak tersedia dengan BAB di Sungai sebanyak 25 KK $(43,1 \%)$ dan BAB di jamban sebanyak 0 KK $(0,0 \%)$. Dari hasil uji statistik diperoleh $p$-Value 0,000 $<0,05 \mathrm{Ho}$ ditolak, berarti ada hubungan yang bermakna antara ketersediaan jamban dengan BAB. Hasil analisis diperoleh juga nilai OR tidak ditemukan dikarenakan $p$ Value yang di dapat yaitu sebesar 0,000 artinya responden yang memiliki ketersediaan jamban yang tidak tersedia mempunyai peluang untuk memiliki ketersediaan jamban yang tersedia. Pengamatan dan pemberian kuesioner kepada responden yang dilakukan oleh peneliti didapatkan hasil bahwa untuk ketersediaan jamban yang dimiliki oleh masyarakat yang menjadi responden atau sampel yang bertempat tinggal di pinggiran sungai ada yang $B A B$ di sungai dan ada yang memiliki Jamban dirumah. Responden yang memiliki jamban dirumah tidak semuanya memiliki septictankuntuk penampungan tinja. Masyarakat tidak memiliki septictankdikarenakan biaya pembuatan septictank mahal sehingga masyarakat enggan untuk membuat septictank. Selain biaya yang mahal, kondisi lingkungan yang tidak mendukung untuk pembuatan septictank karena di kelurahan legok sering terjadi banjir. Masyarakat berfikir bahwa pembuatan septictanktidak efektif apabila pada saat banjir. Sehingga masyarakat lebih memilih menggunakan pipa yang dihubungkan dari Jamban yang ada dirumah langsung diarahkan ke sungai kecil yang ada di Kelurahan Legok. Akan tetapi pada saat banjir, sungai yang disalurkan pipa dari Jamban dari rumah masyarakat akan terendam air. Sehingga pipa yang dialirkan ke sungai tidak dapat berfungsi dengan baik karena pipa tertutup oleh air sungai yang meluap akibat banjir. Dan apabila tidak pada saat banjir, masyarakat yang menggunakan pipa yang dihubungkan ke Jamban dirumah dan dialirkan ke sungai akan mengakibatkan pencemaran pada air sungai. Sebagian masyarakat yang bertempat tinggal dipinggiran sungai, juga masih menggunakan air sungai untuk kegiatan mandi, cuci, dan kakus (MCK). Padahal air sungai yang digunakan untuk kegiatan MCK tersebut sudah tercemar oleh tinja 
melalui pipa yang dihubungkan ke jamban yang dimiliki oleh masyarakat. Penularan penyakit melalui air sungai juga dapat terjadi, karena air sungai sering digunakan untuk berbagai keperluan dan aktifitas seperti mandi, cuci, dan tempat untuk buang air besar. (Proverawati, 2012). Peneliti menyarankan agar masyarakat membuat arisan jamban untuk pembuatan jamban dan septictank untuk masyarakat yang belum memiliki jamban dan septictank. Dan peneliti juga menyarankan agar mengusulkan pembuatan septictank kepada RT kemudian RT mengusulkan kepada Lurah dan seterusnya hingga sampai ke Dinas Pekerjaan Umum.

\section{Hubungan Perilaku Dengan BAB}

Hasil diketahui bahwa perilaku masyarakat di pinggiran, sungai yang baik dengan $B A B$ di sungai sebanyak $0 \mathrm{KK}(0,0 \%)$ dan BAB di jamban sebanyak 37 KK (100,0\%). Sedangkan untuk perilaku masyarakat di pinggiran sungai yang kurang baik dengan $B A B$ di sungai sebanyak $25 \mathrm{KK}(50,0 \%)$ dan $\mathrm{BAB}$ di jamban sebanyak $25 \mathrm{KK}(50,0 \%)$. Dari hasil uji statistik diperoleh p-Value 0,002 < 0,05 Ho ditolak, berarti ada hubungan yang bermakna antara perilaku masyarakat BAB. Hasil analisis diperoleh juga nilai $\mathrm{OR}=5,920$ artinya responden yang memiliki perilaku yang kurang baik mempunyai peluang 5,92 kali untuk BAB di jamban dibandingkan dengan responden memiliki perilaku baik yang $B A B$ di Jamban. Pengamatan dan wawancara yang dilakukan peneliti saat pengambilan data di lapangan, ditemukan adanya masyarakat yang bertempat tinggal di pinggiran sungai memiliki perilaku yang baik dan kurang baik. Untuk responden yang memiliki perilaku baik, responden mencuci tangan pakai sabun setelah $B A B$ sedangkan untuk perilaku yang kurang baik, responden tidak mencuci tangan pakai sabun setelah BAB. Responden yang tidak mencuci tangan pakai sabun setelah $B A B$, mereka melakukan aktivitas buang air besar di sungai dan di Jamban. Responden tidak mencuci tangan pakai sabun setelah $B A B$ dikarenakan responden tidak terbiasa mencuci tangan menggunakan sabun. Mereka terbiasa hanya membersihkan tangan menggunakan air saja tanpa menggunakan sabun. Padahal mencuci tangan menggunakan sabun setelah buang air besar adalah termasuk untuk mencegah penularan penyakit yang disebabkan oleh tinja. Menurut maulana (2009) perilaku merupakan hasil pengalaman dan proses interaksi dengan lingkungannya, yang terwujud dalam bentuk pengetahuan, sikap, dan tindakan sehingga diperoleh keadaan penahan. Perilaku seseorang dapat berubah jika terjadi ketidakseimbangan antara kedua kekuatan di dalam diri seseorang. Perilaku masyarakat yang baik akan mempunyai hubungan yang bermakna dengan BAB masyarakat di Jamban, karena dengan memiliki perilaku yang baik akan mendorong seseorang untuk melakukan BAB di Jamban untuk mencegah agar tidak ada lagi masyarakat yang melakukan $B A B$ di sungai.

Peneliti menyarankan agar responden mencuci tangan memakai sabun setelah melakukan BAB.

\section{Hubungan Pengetahuan Dengan BAB}

Hasil diketahui bahwa pengetahuan masyarakat yang ada dipinggiran sungai yang baik dengan BAB di sungai sebanyak $10 \mathrm{KK}(16,9 \%)$ dan $\mathrm{BAB}$ di Jamban sebanyak 49 KK (83,15\%) sedangkan untuk pengetahuan masyarakat yang ada di pinggiran sungai yang kurang baik sebanyak $15 \mathrm{KK}(53,6 \%)$ dan $\mathrm{BAB}$ di jamban sebanyak $13 \mathrm{KK}(46,4 \%)$. Dari hasil uji statistik diperoleh $p$-Value 0,001 <0,05 Ho ditolak, berarti ada hubungan yang bermakna antara pengetahuan masyarakat dengan BAB. Hasil analisis juga diperoleh nilai $\mathrm{OR}=5,654$ artinya responden yang memiliki pengetahuan kurang baik mempunyai peluang 5,65 kali untuk $B A B$ di jamban dibandingkan dengan pengetahuan yang baik untuk BAB di jamban. Pengamatan dan wawancara yang dilakukan peneliti saat pengambilan data di lapangan, ditemukan responden yang memiliki pengetahuan yang baik dan kurang baik. Pengetahuan responden baik karena rata-rata responden lulusan SMA. Sedangkan responden yang memiliki pengetahuan kurang baik disebabkan karena responden lulusan SD dan SMP. Kuesioner yang telah terisi tentang pengetahuan jamban didapatkan hasil bahwa kurangnya pengetahuan responden tentang persyaratan jamban keluarga dan manfaat apabila menggunakan jamban keluarga. Responden yang mempunyai pengetahuan baik akan tetapi masih $B A B$ di sungai. Responden mempunyai alasan yaitu responden tidak terbiasa $B A B$ di jamban, responden sudah terbiasa dengan melakukan $B A B$ di sungai. Sehingga walaupun responden mempunyai pengetahuan yang baik responden terbiasa $B A B$ disungai. Menurut proverawati (2012) syarat jamban yang sehat adalah tidak mencemari sumber air minum (jarak antara sumber air minum dengan lubang penampungan minimal 10 meter), tidak berbau, kotoran tidak dapat dijamah oleh serangga dan tikus, tidak mencemari tanah sekitarnya, mudah dibersihkan dan aman digunakan, dilengkapi dinding dan atap pelindung, penerangan dan ventilasi cukup, lantai kedap air dan luas ruangan memadai, dan tersedianya air, sabun, dan alat pembersih. Sehingga apabila Jamban dirumah memenuhi persyaratan maka dapat dikatakan jamban dirumah termasuk jamban sehat. Menurut Fitriani (2011), Pengetahuan merupakan hasil tahu dan ini terjadi setelah orang melakukan pengindraan terhadap suatu objek tertentu. Sebagian besar pengetahuan manusia diperoleh melalui mata dan telinga. Sehingga tingkat pengetahuan masyarakat bisa didapat dari pada saat masyarakat melihat sesuatu yang postif dan mendengar sesuatu yang positif akan mendorong masyarakat yang mempunyai pengetahuan kurang baik untuk menjadi masyarakat yang mempunyai pengetahuan baik tentang jamban. Peneliti menyarankan agar petugas puskesmas bagian kesehatan lingkungan sebaiknya melakukan penyuluhan kepada masyarakat tentang jamban sehat sehingga masyarakat mengerti dan paham tentang jamban sehat. Dan masyarakat memiliki pengetahuan yang kurang baik tentang jamban bisa bertanya kepada petugas puskesmas bagian kesehatan lingkungan tentang jamban yang sehat dan juga bertanya kepada orang yang mengerti dan paham tentang jamban sehat. 


\section{SIMPULAN DAN SARAN}

\section{Kesimpulan}

1. Ada hubungan yang bermakna ketersediaan jamban dengan BAB di Kelurahan Legok Kecamatan Danau Sipin Kota Jambi dengan nilai $p$-Value $=0,000$.

2. Ada hubungan yang bermakna perilaku dengan buang BAB di Kelurahan Legok Kecamatan Danau Sipin Kota Jambi dengan $p$-Value $=0,002$.

3. Ada hubungan yang bermakna pengetahuan dengan BAB di Kelurahan Legok Kecamatan Danau Sipin Kota Jambi dengan $p$-Value $=0,001$.

\section{DAFTAR PUSTAKA}

Adnani, H, 2011Buku Ajar Ilmu Kesehatan Masyarakat.Nuha Medika, Yogyakarta

Arikunto, S, 2005. Manajemen Penelitian. PT.Rineka Cipta, Jakarta

Chandra,Budiman, 2012.Pengantar Kesehatan Lingkungan.Penerbit Buku Kedokteran EGC, Jakarta

Dianawuri, 2009. Arti Defekasi. http://dianawuri.multiply.com/journal. Diunduh : 9 Juni 2016

Dinas Kesehatan Kota Jambi, 2017. Laporan Tahunan Kepemilikan Jamban Di Kota Jambi

Fitriani, Sinta, 2011.Promosi Kesehatan. Graha IImu, Yogyakarta

Maulana, 2009. Promosi Kesehatan. Penerbit Buku Kedokteran EGC, Jakarta

Mubarak,W,2009. IImu Kesehatan Masyarakat Teori dan Aplikasi. Salemba Medika, Jakarta

Notoatmodjo, Soekidjo, 2007 "Pendidikan dan Perilaku Kesehatan", PT. Rineka Cipta, Jakarta 2010. IImu Perilaku Kesehatan. PT.Rineka Cipta, Jakarta 2012. Promosi Kesehatan dan Perilaku Kesehatan. PT.Rineka Cipta, Jakarta 2014. Kesehatan masyarakat : IImu dan Seni. PT.Rineka Cipta, Jakarta

Priyoto, 2015.Perubahan dalam perilaku kesehatan konsep dan seni. Graha IImu, Yogyakarta

Proverawati.Rahmawati, 2012.Perilaku Hidup Bersih Dan Sehat.Nuha Medika, Yogyakarta

Riyanto,A, 2011.Aplikasi Metodologi Penelitian Kesehatan.Nuha Medika, Yogyakarta

Soedarto, 2013.Lingkungan dan Kesehatan.CV.Sagung Seto, Jakarta

Triwibowo,C, Pusphandani Mitha, 2013.Kesehatan Lingkungan dan K3.Nuha Medika, Yogyakarta 